\title{
SARS-CoV-2 respiratory screening of asymptomatic stem cell donors on day of collection; to test or not to test. UK Aligned Stem Cell Donor Registry
}

(c) The Author(s), under exclusive licence to Springer Nature Limited 2021

Bone Marrow Transplantation (2021) 56:2595-2596; https://doi.org/10.1038/s41409-021-01379-7

\section{TO THE EDITOR:}

Since the emergence of the novel human coronavirus, SARS-CoV-2 in December 2019, the virus has spread worldwide. This pandemic brought significant disruption to haematopoietic cell transplantation (HCT), in terms of safety for high-risk patients, donor health and availability, transport logistics, and staffing and capacity concerns. There was initial theoretical concern about risk of transmission through blood products to highly immunocompromised recipients, risk to donor health of G-CSF mobilisation during SARS-CoV-2 infection, and public health implications of potentially positive donors attending collection centres. Here we report a case of SARS-CoV-2 RNA positivity in both respiratory swab and plasma of an otherwise asymptomatic unrelated stem cell donor on the day of peripheral blood stem cell collection (PBSC), and discuss the current rationale for testing and implications for donor provision.

Whilst the diagnosis of SARS-CoV-2 infection centres on viral RNA detection from the respiratory tract, viral RNA can be detected in other bodily fluids including plasma. The significance of viral RNA in blood, termed RNA-aemia, with regards severity of infection and potential to represent viable replication competent virus, is less well established [1].

Other respiratory viruses, influenza, SARS-CoV and MERS are not known to be transmitted by blood products, despite possible detection of viral RNA in plasma [1, 2] and there have been no reported cases of transfusion-transmitted SARS-CoV-2 infection.

Many stem-cell donor registries do not require testing of asymptomatic stem-cell donors or quarantine of products, opting for screening for symptoms and contacts, advising not to donate if recent contact or symptomatic, warranting a deferral in these cases [3]. In the UK, NICE guidelines recommended SARS-CoV-2 respiratory PCR testing of all stem-cell donors pre-conditioning for fresh cells and on day of collection for cryopreserved collections, a practice adopted by the UK Aligned Donor registries [4]. If respiratory-PCR positive, NICE recommends the clinical team and recipient make a clinical decision over the use of these cells [4].

A 26-year-old male unrelated UK donor was requested for a recipient for PBSC donation intended for cryopreservation. SARSCoV-2 RNA was negative on respiratory swab (Anatolia Geneworks Bosphere) at medical assessment. Two weeks later he commenced G-CSF mobilisation ( $10 \mathrm{mcg} / \mathrm{kg} \mathrm{s} / \mathrm{c}$ once daily for 4 days). He retrospectively reported bone pain and myalgia which he attributed to expected side effects. He did not experience temperature $>37.8^{\circ}$, shortness of breath, cough, or anosmia. On day of collection he was clinically well. A routine respiratory viral PCR was positive (AGB assay) with results available postprocedure. The collection yielded $4.12 \times 10^{\wedge} 6$ CD34 cells $/ \mathrm{kg}$. The transplant centre was informed and opted to proceed with another donor. The donor remained asymptomatic. SARS-CoV-2 RNA was detected in a plasma sample from the day of collection (Procleix SARS-CoV-2 RNA, validated, qualitative TMA assay with a $95 \%$ limit of detection of 26 copies $/ \mathrm{ml}$ in plasma); the positive signal obtained was reproducible on repeat testing. Samples were obtained 6 weeks later showing SARS-CoV-2 lgG seroconversion and undetectable RNA in plasma.

SARS-CoV-2 RNA has been detected in plasma of individuals with severe COVID-19 at variable frequencies $[5,6]$ but less frequently in asymptomatic individuals [7, 8]. A study of blood donors at Wuhan blood centre, with 1656 prospectively and 4995 retrospectively screened by RT-PCR on plasma, showed four positive donors, two remained asymptomatic and two developing fevers shortly after donation [8]. Collected units were discarded. A systematic literature review found considerable heterogenicity in RNA SARS-CoV-2 positivity in blood from $0 \%$ to up to $76 \%$ in Covid-19 patients. Pooling from data, the point estimate for the prevalence of viral RNA in blood samples in the 28 days following symptomatic infection is $10 \%$ with RNA-aemia more likely in those with more severe disease [9]. The question remains whether RNAaemia simply reflects detection of genomic fragments rather than replication-competent virus capable of transmitting infection. To assess risk of transmission through aerolization of blood, this group studied prevalence of RNA-aemia in SARS-CoV-2 in-patients and staff ( $12 \%$ with RNA-aemia) and attempted virus isolation from a subset of RNA positive samples which did not yield replication competent virus, suggesting negligible risk of transmission through this route [9]. The French hemovigilance network investigated the presence of SARS-CoV-2 RNA in the plasma of blood donors reporting COVID-19-like symptoms post-donation or in donations involved in recipient-initiated trace-back studies. 268 individuals with post-donation symptoms were investigated with three testing positive for SARS-CoV-2 RNA in plasma. In one of these, products had been transfused, one red cell unit to a Covid19 recipient, and one pathogen reduced platelet unit to a recipient who remained asymptomatic. Infectivity of RNA-positive plasma was not evidenced in cell culture experiments, and recipient-initiated traceback yielded no positive donations, again providing reassurance on the safety of transfusion [10]. The transfused platelets were pathogen reduced, not something performed in PBSC or bone marrow (BM) collections. The role of cellular content, and presence of intact virions or replication competent viruses within mononuclear cells requires interrogation. A case report of PBSC donations from two asymptomatic related donors that were SARS-CoV-2 RNA-positive on respiratory swab on day of donation did not show transmission of infection to recipients [11] and BM donation from a SARS-CoV-2 positive donor 
on respiratory swab (with negative RNA testing of BM product), also did not show transmission [12].

This case shows detectable RNA-aemia in a healthy stem cell donor testing SARS-CoV-2 positive on respiratory swab, without displaying classic symptoms of Covid-19, but in whom nonspecific symptoms may overlap with G-CSF side effects. Whilst all registries defer on the basis of symptoms, the UK stem cell donor registries are one of the few that perform SARS-CoV-2 RNA screen in nasopharynx samples from all donors. Development of confirmed Covid-19 or suggestive symptoms early post-donation may risk cryopreserved donations not being used due to uncertainty. To date we are aware of three UK aligned registry donors developing symptoms and testing positive within $72 \mathrm{~h}$ post-donation, out of 537 collections. The product was infused in one case (negative Respiratory-PCR on day of collection), and discarded in two. A negative respiratory SARS-CoV-2 RNA test, with high sensitivity and specificity, from day of donation may therefore provide reassurance in these instances.

Concerns exist that testing healthy stem-cell donors of cryopreserved products leads to unnecessary worry about transmission risk and subsequent wastage of collected products. This case does not advocate for automatic discarding of products in donors SARS-CoV-2 RNA-positive on respiratory swab. Transplant centres can consider proceeding with the donation as planned given the reassuring lack of reported transfusiontransmitted cases or evidence of viable replication competent virus isolated from RNA-positive samples in studies to date [9-12]. They can make informed decisions with all available information, including investigating for presence of RNA-aemia as in this case, and discussions with the recipient [4].

Understanding donor respiratory RNA prevalence allows for appropriate surveillance and monitoring of a recipient post stemcell infusion if a transplant centre opts to proceed, as well as adding to the body of reassuring evidence about safety in these instances thus far, which without testing we would be less equipped to answer. With the emergence of new variants, such as B1.1.7, 501Y. V2 and B.1.617, continuing with donor respiratory testing for SARSCoV-2 RNA on day of collection, with blood viral PCR follow up testing if requested, could help us better understand the implications and contribute to existing evidence on safety.

$$
\begin{array}{r}
\text { Angharad Pryce }{ }^{1 凶},{ }^{1} \text { Farheen Mir }{ }^{1} \text {, Ines Ushiro-Lumb }{ }^{2}, \\
\text { Roman Drypen }{ }^{3}, \text { Ellie Moss }{ }^{3}, \text { Helen Kelly }{ }^{3}, \text { Ann O'Leary }{ }^{1}, \\
\text { Rachel Pawson }{ }^{2} \text { and Robert Danby }{ }^{1} \\
{ }^{1} \text { Anthony Nolan, London, UK. }{ }^{2} \text { British Bone Marrow Registry, NHS } \\
\text { Blood and Transplant, Bristol, UK. }{ }^{3} \text { DKMS UK, London, UK. } \\
\text { @email: Angharad.pryce@anthonynolan.org }
\end{array}
$$

\section{REFERENCES}

1. Chang L, Yan Y, Wang L. Coronavirus Disease 2019: coronaviruses and blood safety. Transfus Med Rev. 2020;34:75-80.
2. Choi S-M, Xie H, Campbell A, Kuypers J, Leisenring W, Boudreault AA, et al. Influenza Viral RNA detection in blood as a marker to predict disease severity in hematopoietic cell transplant recipients. J Infect Dis. 2012;206:1872-7.

3. COVID-19 - Impact on Registry Operations - Home Page - Share (https://wmda. info) (Accessed 11 Feb 2021)

4. Covid-19 rapid guideline: haematopoietic stem cell transplantation. NICE Guideline [NG164] https://www.nice.org.uk/guidance/ng164 (Accessed 11 Feb 2021)

5. Chen W, Lan Y, Yuan X, Deng X, Li Y, Cai X, et al. Detectable 2019-nCoV viral RNA in blood is a strong indicator for the further clinical severity. Emerg Microbes Infect. 2020;9:469-73.

6. Zheng S, Fan J, Yu F, Feng B, Lou B, Zou Q, et al. Viral load dynamics and disease severity in patients infected with SARS-CoV-2 in Zhejiang province, China, January-March 2020: retrospective cohort study. BMJ. 2020;369:m1443.

7. Corman VM, Rabenau H, Adams O, Oberle D, Funk MB, Keller-Stanilawski BK, et al. SARS-CoV-2 asymptomatic and symptomatic patients and risk for transfusion transmission. Transfusion. 2020;00:1-4.

8. Chang L, Zhao L, Gong H, Wang L, Wang L. Severe acute respiratory syndrome coronavirus 2 RNA detected in blood donations. Emerg Infect Dis. 2020;7:1631-3.

9. Andersson M, Arancibia-Carcamo C, Auckland K, Baillie JK, Barnes EJ, Beneke T, et al. SARS-CoV RNA detected in blood products from patients with Covid-19 is not associated with infectious virus. Wellcome Open Res. 2020;5:181.

10. Cappy P, Candotti D, Sauvage V, Lucas Q, Boizeau L, Gomez J, et al. No evidence of SARS-CoV-2 transfusion transmission despite RNA detection in blood donors showing symptoms after donation. Blood. 2020;136:1888-91.

11. Lecler M, Fourant S, Menouche D, Challine D, Maury S. Allogeneic haematopoietic stem cell transplantation from SARS-CoV-2 positive donors. Lancet Haematol. 2020. https://doi.org/10.1016/S2352-3026(21)00025-9.

12. Anurathapan $U$, Apiwattanakul N, Pakakasama S, Pongphitcha $P$, Thitithanyanont A, Pasomsub E, et al. Hematopoietic stem cell transplantation from an infected SARS-CoV2 donor sibling. Bone Marrow Transpl. 2020;55:2359-2360.

\section{ACKNOWLEDGEMENTS}

We would like to acknowledge and thank all staff at the UK Aligned Stem Cell Registry (Anthony Nolan, DKMS-UK, NHSBT-BBMR and WBMDR). We would also like to thank all the staff at the donor Collection Centres throughout the UK, and our colleagues working in the Transplant Centres.

\section{COMPETING INTERESTS}

The authors declare no competing interests.

\section{ADDITIONAL INFORMATION}

Correspondence and requests for materials should be addressed to A.P.

Reprints and permission information is available at http://www.nature.com/ reprints

Publisher's note Springer Nature remains neutral with regard to jurisdictional claims in published maps and institutional affiliations. 